\section{Commentary: First rib resection in the age of robotic surgery}

\author{
Harmik J. Soukiasian, MD, FACS
}

Thoracic outlet syndrome (TOS) may have various root causes, namely, neurogenic, venous, and arterial TOS. The vast majority of TOS cases, approximately $95 \%$, are neurogenic. Venous $(3 \%)$ and arterial $(1 \%-2 \%)$ causes combine to make up the remaining $5 \%{ }^{1,2}$

Resection of the first rib allows for thoracic outlet decompression, providing a wider berth through which the neurovascular structures may pass without impingement or encroachment. This may not only require first rib resection but may also include resection of a cervical rib, venolysis, scalenectomy, and division of anomalous bands or musculotendinous insertions.

The approach to first rib resection is quite varied, with no single approach regarded as the criterion standard. Several methods have been described, including supraclavicular, infraclavicular, transaxillary, high posterior thoracoplasty, video-assisted thoracoscopic, and robotic approaches. The approach generally depends on the anatomic abnormality requiring correction, clinical presentation, and surgeon preference. $^{3-8}$ This is exemplified by the treatment of Paget-Schroetter syndrome, in which some advocate patch angioplasty of the vein in addition to thoracic outlet decompression. This approach usually necessitates an infraclavicular incision, which allows adequate control of the subclavian vein to sew in a patch. ${ }^{9}$

Treatment of TOS risks injuring the neurovascular structures that surround the first rib. Surgeons who use the supraclavicular approach site perform a thorough venolysis or neurolysis that those who use the VATS approach may struggle to achieve. In this article, however, Burt and colleagues ${ }^{10}$ describe their surgical approach to first rib resection with the da Vinci Xi Robot (Intuitive,

\footnotetext{
From the Division of Thoracic Surgery, Department of Surgery, Cedars-Sinai Medical Center, Los Angeles, Calif.

Disclosures: Dr Soukiasian is a speaker for Medtronic and a proctor for Intuitive Surgery. Received for publication Dec 17, 2019; revisions received Dec 17, 2019; accepted for publication Jan 3, 2020; available ahead of print Feb 19, 2020.

Address for reprints: Harmik J. Soukiasian, MD, FACS, Division of Thoracic Surgery, Department of Surgery, Cedars-Sinai Health System, 8631 W 3rd St, Suite 240 E, Los Angeles, CA 90048 (E-mail: Harmik.Soukiasian@cshs.org).

JTCVS Techniques 2020;1:112-3

2666-2507

Copyright (c) 2020 The Author(s). Published by Elsevier Inc. on behalf of The American Association for Thoracic Surgery. This is an open access article under the CC BY-NC-ND license (http://creativecommons.org/licenses/by-nc-nd/4.0/).

https://doi.org/10.1016/j.xjtc.2020.01.004
}

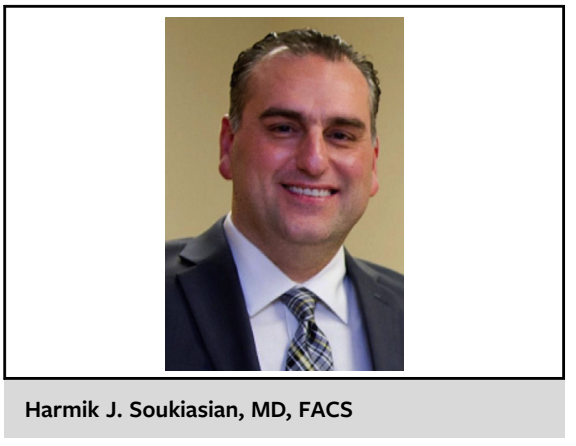

CENTRAL MESSAGE

As experience with robotic sur-

gery grows, surgeons are

applying the improved visualiza-

tion and dexterity of instrumen-

tation to allow safe surgery in

expanded indications, such as

first rib resection.

Sunnyvale, Calif). They demonstrate the controlled and delicate dissection of the neurovascular structures, confirming that thorough and safe venolysis or neurolysis is possible with the robotic approach. In addition, they perform a complete or nearly complete resection of the rib, especially the posterior aspect, which Mingoli and colleagues $^{11}$ have cited as the strongest determinant of long-term results.

The learning curve of any procedure is an important variable to keep in mind when considering how reproducible the results and techniques of a described approach are. Knowing the learning curve of the procedure for Burt and colleagues ${ }^{10}$ would help better elucidate the reproducibility of this technique for surgeons familiar with video-assisted thoracoscopic surgery as well as robotic surgery, in addition to those surgeons not experienced with minimally invasive approaches.

As technology and instrumentation continue to advance in thoracic surgery, so will the boundaries of the surgeon's comfort with adoption of new and emerging techniques and radical approaches to current problems. For example, in TOS requiring venous patch angioplasty, the surgeon may choose to complete the operation robotically. Rather than use an infraclavicular approach, the advanced robotic surgeon may attempt to gain proximal and distal control robotically and sew the patch in with the robot as well, thus pushing the boundaries, as has been demonstrated with robotic vascular sleeve 
resections. As with most disease states, there is more than one way to approach decompression of the thoracic outlet and first rib resection. The most important determinant remains surgeon ability to perform the selected approach safely and efficaciously.

\section{References}

1. Cormier JM, Amrane M, Ward A, Laurian C, Gigou F. Arterial complications of the thoracic outlet syndrome: fifty-five operative cases. J Vasc Surg. 1989;9:778-87.

2. Hood DB, Kuehne J, Yellin AE, Weaver FA. Vascular complications of thoracic outlet syndrome. Am Surg. 1997;63:913-7.

3. Urschel HC Jr, Razzuk MA. Paget-Schroetter syndrome: what is the best management? Ann Thorac Surg. 2000;69:1663-8; discussion 1668-9.

4. Chang KZ, Likes K, Demos J, Black JH III, Freischlag JA. Routine venography following transaxillary first rib resection and scalenectomy (FRRS) for chronic subclavian vein thrombosis ensures excellent outcomes and vein patency. Vasc Endovascular Surg. 2012;46:15-20.
5. Sanders RJ, Hammond SL. Supraclavicular first rib resection and total scalenectomy: technique and results. Hand Clin. 2004;20:61-70.

6. Roos DB. Transaxillary approach for first rib resection to relieve thoracic outlet syndrome. Ann Surg. 1966;163:354-8.

7. Soukiasian HJ, Shouhed D, Serna-Gallgos D, McKenna R III, Bairamian VJ, McKenna RJ Jr. A video-assisted thoracoscopic approach to transaxillary first rib resection. Innovations (Phila). 2015;10:21-6.

8. Abdellaoui A, Atwan M, Reid F, Wilson P. Endoscopic assisted transaxillary first rib resection. Interact Cardiovasc Thorac Surg. 2007;6:644-6.

9. Molina J, Jaklitsch MT. Thrombosis of the subclavian vein: PagetSchroetter syndrome. In: Sugarbaker DJ, Bueno R, Colson YL, Jaklitsch M, Krasna MJ, Mentzer S, eds. Adult Chest Surgery. 2nd ed. New York: McGraw-Hill; 2015.

10. Burt B, Palivela N, Karimian A, Goodman MB. Transthoracic robotic firs rib resection: Twelve steps. J Thorac Cardiovasc Surg Tech. 2020;1 104-9.

11. Mingoli A, Feldhaus RJ, Farina C, Cavallari N, Sapienza P, di Marzo L, et al Long-term outcome after transaxillary approach for thoracic outlet syndrome. Surgery. 1995;118:840-4. 